\title{
Modelling of the dynamic behaviour of profiled composite floors
}

\author{
Emad El-Dardiry, Tianjian Ji* \\ School of Mechanical, Aerospace and Civil Engineering, The University of Manchester, PO Box 88, Manchester M60 1QD, UK
}

Received 1 June 2005; received in revised form 10 August 2005; accepted 14 September 2005

Available online 24 October 2005

\begin{abstract}
The paper develops an isotropic and an orthotropic flat plate models for predicting simply and reasonably accurately the dynamic behaviour of composite floors. Based on the observation that the mode shapes of a multi-panel floor are different and complicated but the mode shape of each panel is either concave or convex, the two equivalent flat plate models are developed using the equivalence of the maximum displacement of a sophisticated 3D composite panel model. Thin shell elements are used to model the steel sheet and 3D-solid elements to represent the concrete slab. Parametric studies are conducted to examine the effects of boundary condition, loading condition, shear modulus and steel sheet on the equivalent models. The two simplified flat plate models are then applied to studying the dynamic behaviour of a full-scale multi-panel profiled composite floor $(45.0 \mathrm{~m} \times 21.0 \mathrm{~m})$ in the Cardington eight-storey steel framed building. The predicted and measured natural frequencies are reasonably close. The modelling process becomes easier and significant time saving is achieved when either of the two simplified models is used. It is found from the study that the variation of floor thickness due to construction can significantly affect the accuracy of the prediction and the locations of neutral axes of beams and slabs are not sensitive to the prediction providing that they are considered in the analysis.
\end{abstract}

(c) 2005 Elsevier Ltd. All rights reserved.

Keywords: Dynamic behaviour; Composite floors; Flat plates; Modelling; Finite element

\section{Introduction}

Composite floors are widely used in building and bridge construction nowadays. A composite floor is the general term used to denote the composite action of steel beams and concrete or composite slabs that forms a structural floor. The steel decking performs a number of roles in the structural system, such as supporting loads during construction, acting as a working platform to protect workers below, developing composite action with the concrete to resist the imposed loading on the floor and stabilising the beams against lateral buckling $[1,2]$. The design of composite slabs is covered by BS 5950: Part 4 [3].

Serviceability of a composite floor is one of the design considerations, which requires that the fundamental frequency is larger than the trigger value or the floor vibration is less than a limit value. Therefore, the natural frequencies and vibration modes are normally needed. Due to the profiled cross-section, composition of steel decking and concrete slab,

\footnotetext{
* Corresponding author. Tel.: +44 (0) 161306 4604; fax: +44 (0) 161306 4646.

E-mail address: tji@manchester.ac.uk (T. Ji).
}

multi-panels and eccentricities of the floor-beam system, a FE analysis of such a floor becomes challenging. There are limited publications on this topic. Da Silva et al. [4] studied the dynamical behaviour of a composite floor subjected to rhythmic load actions. The composite floor covered an area of $43.7 \mathrm{~m} \times 14.0 \mathrm{~m}$. The $150 \mathrm{~mm}$ thick composite slab included a steel deck of $0.80 \mathrm{~mm}$ thickness and $75 \mathrm{~mm}$ flute height. In the finite element analysis, floor steel girders were represented by three-dimensional beam elements and the composite slab was modelled by shell elements in which only the $75 \mathrm{~mm}$ concrete cover slab was considered. The columns were modelled as hinged supports to the girders.

The effect of columns in the dynamic behaviour of a multi-span concrete building floor was examined [5]. The columns were modelled as vertical pinned supports, fixed supports to the floor and actual columns using 3D beam elements. It was found that the floor-column model provided the best representation of the structure in comparison with eleven frequency measurements of the floor. Therefore, the floor-column model will be adopted in this study.

This paper develops a simplified isotropic and an orthotropic flat plate models based on the equivalence of the maximum 


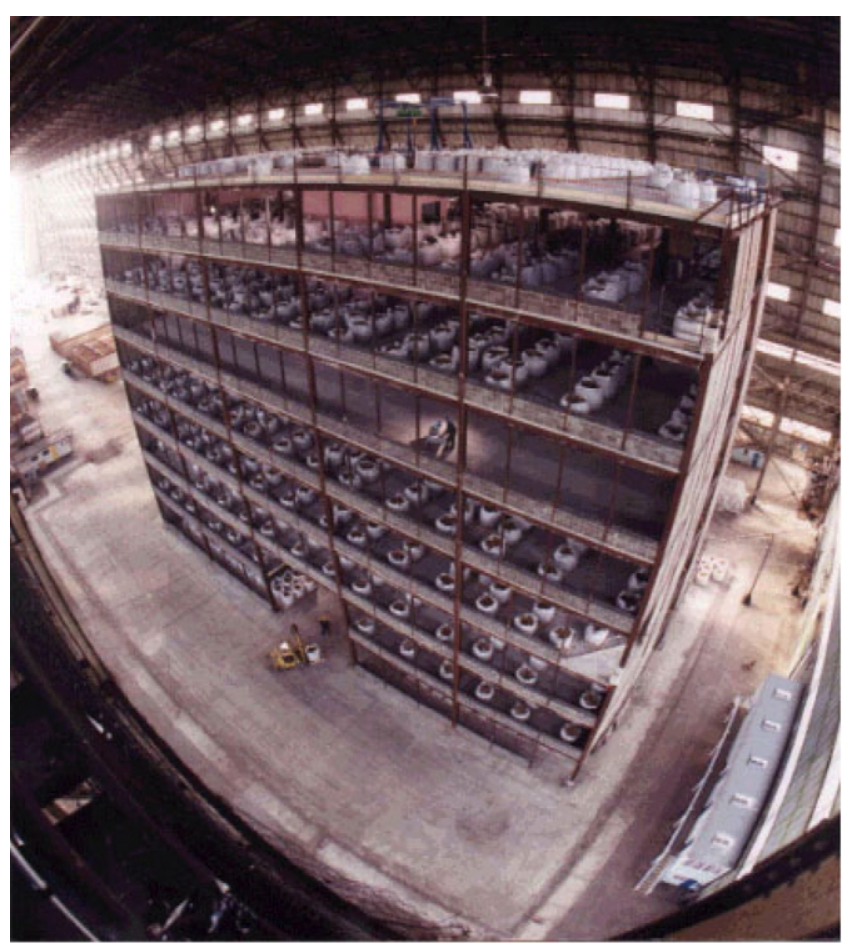

Fig. 1. The steel framed building with floors, walls and static loading [7].

displacement of a 3D simply supported composite deck panel model. The effects of boundary condition, loading condition, shear modulus and the steel sheet on the equivalence are also examined based on the 3D composite floor panel model. The two simplified models are then used to predict the dynamic behaviour of a full-scale composite floor in the Cardington steel framed building. The effects of the eccentricities of beams and slabs and of the variation of floor thickness on the dynamic behaviour of the composite floor are also studied.

\section{The Cardington steel frame building and composite floors}

The development of BRE's large building tests facility at Cardington provided the construction industry with a unique opportunity to carry out full-scale tests on a complete building designed and built to current practice. A steel frame test building was constructed at the Cardington Laboratory in 1994 to resemble an office block. The test building has eight storeys with a height of $33.5 \mathrm{~m}$, five bays with a length of $45.0 \mathrm{~m}$ and three bays with a width $21.0 \mathrm{~m}$ (Fig. 1). The building was designed as a no-sway structure with a central lift shaft and two staircases that were braced to provide the necessary resistance to lateral construction and wind loads [6]. The construction of the building had been undertaken in five discrete stages [7].

The composite floor system in the test building comprised steel downstand beams acting compositely with a floor-slab, constructed using a trapezoidal steel deck (PMF CF70) as shown in Fig. 2, lightweight concrete, and an anti-crack A142 steel mesh. The overall depth of the slab was $130 \mathrm{~mm}$ thick, with the mesh placed $15 \mathrm{~mm}$ above the steel deck. A typical cross-section through the composite floor is shown in Fig. 3.
Table 1

Sections used for beams and columns

\begin{tabular}{lll}
\hline Floor element & Section & Dimensions $(\mathrm{mm})$ \\
\hline \multirow{3}{*}{ Beams } & Beam 1 & $610 \times 229 \times 101 \mathrm{UB}$ \\
& Beam 2 & $356 \times 171 \times 51 \mathrm{UB}$ \\
& Beam 3 & $305 \times 165 \times 40 \mathrm{UB}$ \\
Columns & Beam 4 & $254 \times 146 \times 31 \mathrm{UB}$ \\
& $\mathrm{C} 1$ & $254 \times 254 \times 89 \mathrm{UC}$ \\
& $\mathrm{C} 2$ & $305 \times 305 \times 137 \mathrm{UC}$ \\
\hline
\end{tabular}

Table 2

Material properties of the floor

\begin{tabular}{llll}
\hline Material & Young's modulus (GPa) & Poisson's ratio & $\begin{array}{l}\text { Material density } \\
\left(\mathrm{kg} / \mathrm{m}^{3}\right)\end{array}$ \\
\hline Steel sheet & 210 & 0.3 & 7800 \\
Concrete & 33.5 & 0.2 & 2000 \\
\hline
\end{tabular}

The composite floor is supported by beams and columns only as shown in Fig. 4. A typical plan of a floor in the third storey and above is given in Fig. 4 [8]. At the ground and first floor levels, the plan arrangements are slightly different with an open entrance area at the centre of the south of the building. The details and the locations of the different sections of beams and columns used for floors 3-7 are shown in Table 1 and Fig. 4 respectively. This forms the background for investigating the dynamic behaviour of composite floors, including the one in the Cardington Building.

\section{Isotropic equivalent flat plate model}

Appropriate models should be developed for modelling correctly the multi-panel composite floors. Fig. 5 shows the first six mode shapes of the long-span concrete building floor [5]. It can be seen that the mode shapes of the floor are combinations of the simple mode shape of each floor panel. Although all the six modes of the floor are significantly different, the mode shape of each panel between supporting columns is relatively simple, i.e., it is either concave or convex. Based on this observation, simpler equivalent flat floor models can be formulated using a 3D sophisticated composite deck panel model.

\subsection{D-model of composite deck panel}

The LUSAS finite element program [9] is used to model and analyse the composite deck models. To build up the 3D-model of a composite deck panel two types of finite element are used as follows:

- Thin shell elements (QSL8) to model the steel sheet.

- 3D-solid elements (HX20) to model the concrete slab.

Table 2 gives the material properties used in the analysis, which are taken from material test results on the steelwork and the concrete [10-12].

Initially the effect of mesh sizes on the dynamic behaviour is studied. Different meshes are considered [13] but they have a negligible effect on the natural frequencies and the maximum 


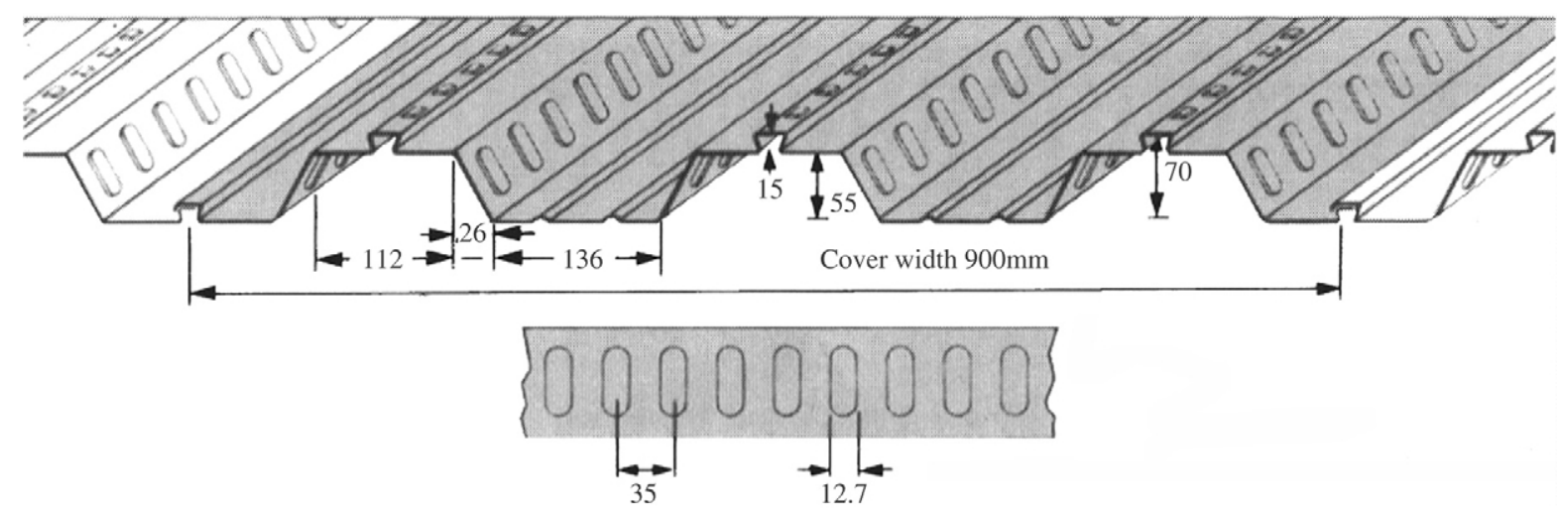

Fig. 2. The profile of a decking sheet (PMF CF70 sheets of $0.9 \mathrm{~mm}$ thickness) [15].

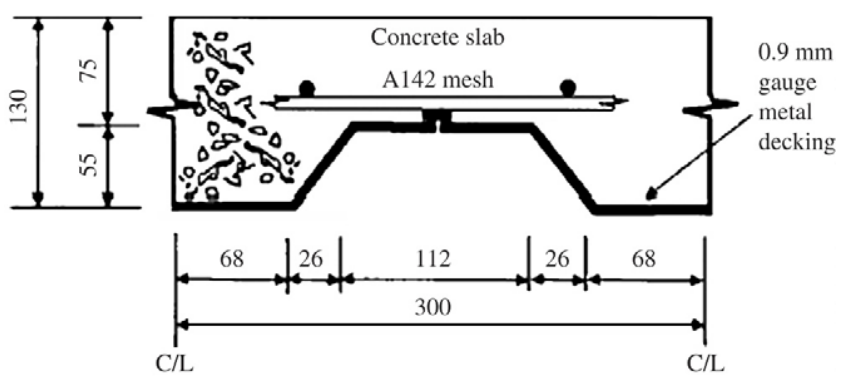

Fig. 3. $300 \mathrm{~mm}$ section through composite floor slab [12].

Table 3

Properties of the isotropic equivalent flat plate and the original 3D-model panel

\begin{tabular}{lll}
\hline The properties & $\begin{array}{l}\text { Original } \\
\text { 3D-model }\end{array}$ & Equivalent isotropic flat plate \\
\hline Dimension $(\mathrm{m})$ & $4.50 \times 3.00$ & $4.50 \times 3.00$ \\
Thickness $(\mathrm{mm})$ & $60 / 130$ & 107.4 \\
Young's modulus $(\mathrm{GPa})$ & $210 / 33.5$ & 33.5 \\
Poisson's ratio & $0.3 / 0.2$ & 0.2 \\
Material density & $7800 / 2000$ & $1.907 \times 10^{3}$ \\
$\left(\mathrm{~kg} / \mathrm{m}^{3}\right)$ & & \\
\hline
\end{tabular}

displacements, although they affect the appearance of the mode shapes. However, a relatively fine mesh is used as it forms a base model for which two simplified models will be developed.

The steel sheet and concrete part are first modelled separately, as shown in Figs. 6(a) and 6(b). Then the two parts are merged to form the composite deck floor model in Fig. 6(c). The compatibility of two parts is considered when modelling the two individual parts. The dimensions of the panel and other properties used in the analysis are given in Table 3.

\subsection{Isotropic equivalent flat plate model}

Based on the theory of isotropic thin flat plates, the maximum deflection of the simply supported flat plate at its centre due to uniformly distributed load is [14]:

$$
\Delta_{\max }=\frac{16 q_{o}}{\pi^{6} D} \sum_{m=1}^{\infty} \sum_{n=1}^{\infty} \frac{(-1)^{\frac{m+n}{2}-1}}{m n\left(\frac{m^{2}}{a^{2}}+\frac{n^{2}}{b^{2}}\right)^{2}}
$$

where: $a=$ length of the plate in

the $x$-direction

$h=$ thickness of the plate

$E=$ Young's modulus

$D=\frac{E h^{3}}{12\left(1-v^{2}\right)}$

The solution of Eq. (1) is given [14] in another form depending on the ratio of the plate dimensions $(a / b)$ as follows:

$\Delta_{\max }=\alpha\left[\frac{q_{o} b^{4}}{D}\right]$

For the ratio $a / b=1.5$ the value of $\alpha$ is 0.00772 .

The equivalent stiffness $(D)$, or thickness $(h)$ in Eq. (2) can be determined when $\Delta_{\max }$ is known, which can be calculated using the 3D FE model of the composite panel (Figs. 6(a), 6(b) and 6(c)). The equivalent mass of the flat plate can be determined based on the condition that the equivalent plate has the same amount of mass as the original composite panel. Table 3 shows the properties of the isotropic equivalent concrete flat plate and the original composite deck panel.

A thin plate element (QSL8) is used to model the isotropic equivalent flat plate. Both static and eigenvalue analyses are conducted. Table 4 gives the comparison between the results of the isotropic equivalent flat panel and the composite deck panel. It can be seen from Table 4 that:

1. The isotropic equivalent thin plate is able to provide the maximum displacement and fundamental natural frequency almost the same as those of the composite plate.

2. The analysis of the isotropic equivalent thin flat plate model only takes about $1 \%$ of CPU time as the 3D-model needs. The CPU time saving can be more significant when dealing with multi-panel composite floors.

3. For obtaining the isotropic equivalent flat plate model, a 3D FE modelling of a composite floor panel is required.

\section{Orthotropic equivalent flat plate model}

Based on the fact that the profile of the decking sheet is different in the two main directions, an orthotropic equivalent flat plate model can be developed without modelling of the 


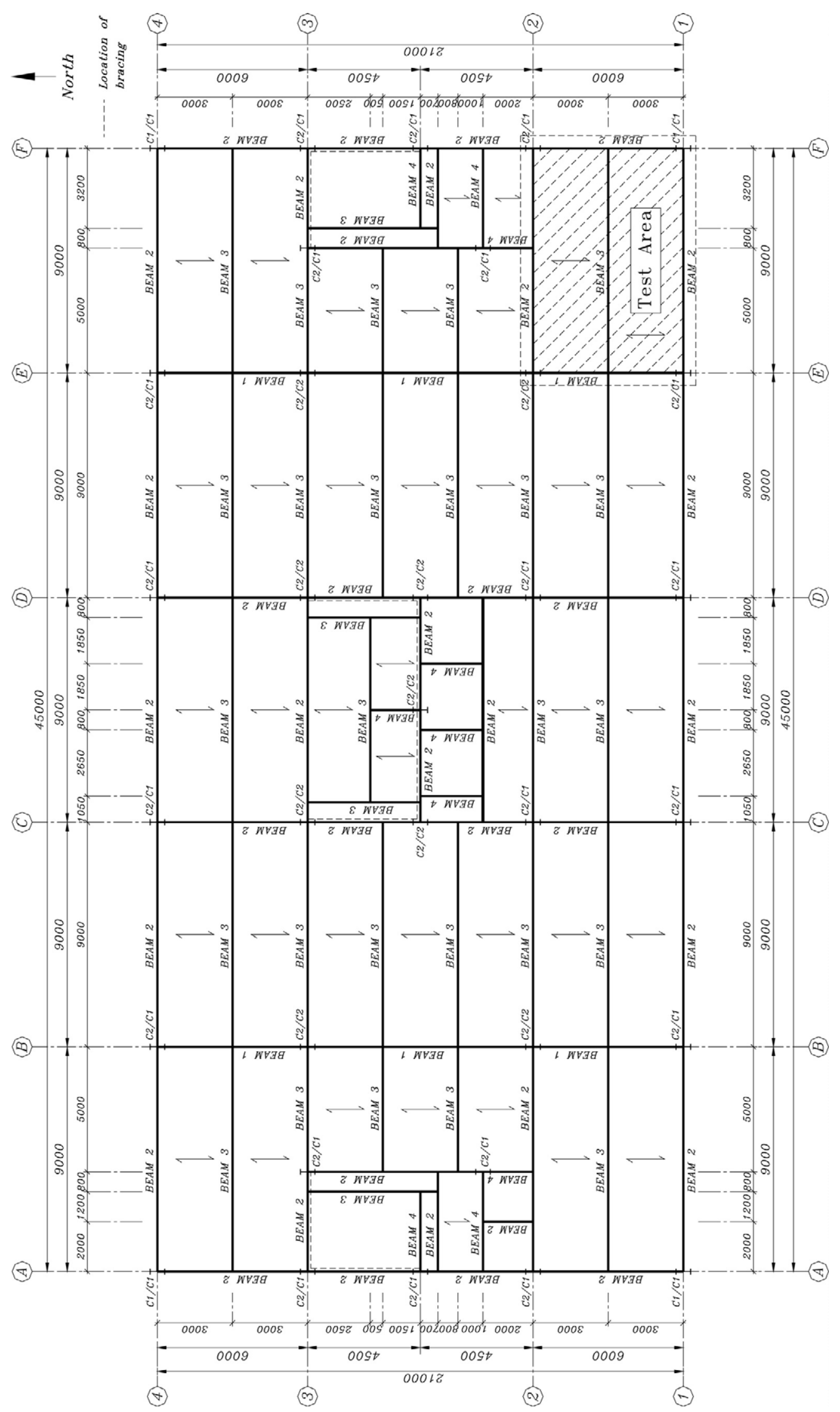

Fig. 4. Typical plan for floors 3-7 of the Cardington steel building [8]. 


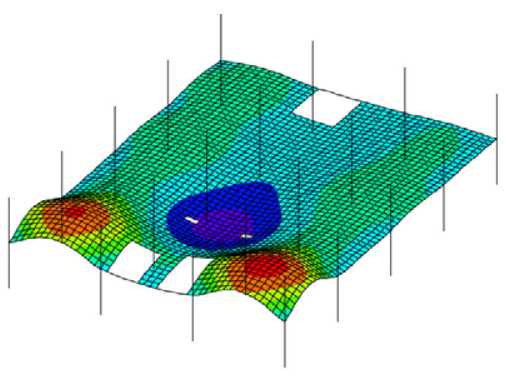

Mode (1) Freq. $=8.25 \mathrm{~Hz}$

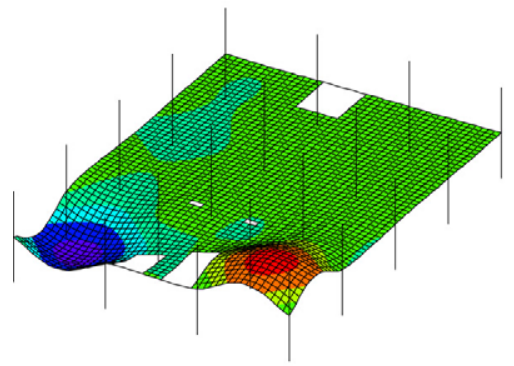

Mode (3)

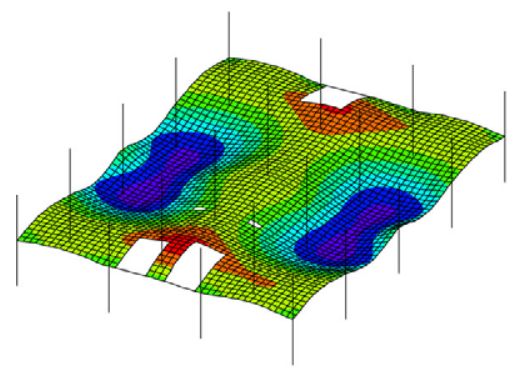

Mode (5) Freq. $=8.96 \mathrm{~Hz}$

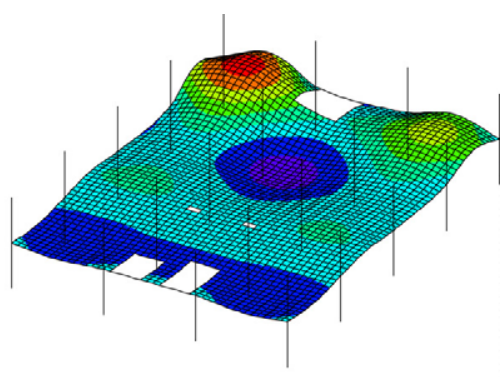

Mode (2)

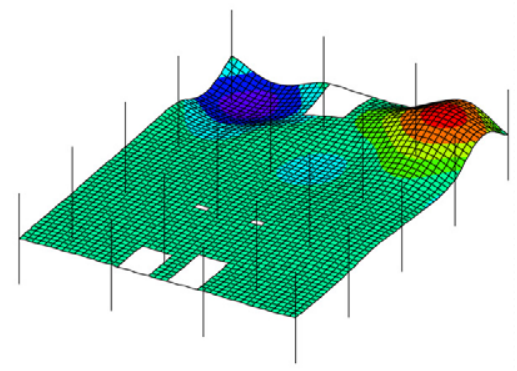

Mode (4)

Freq. $=8.62 \mathrm{~Hz}$

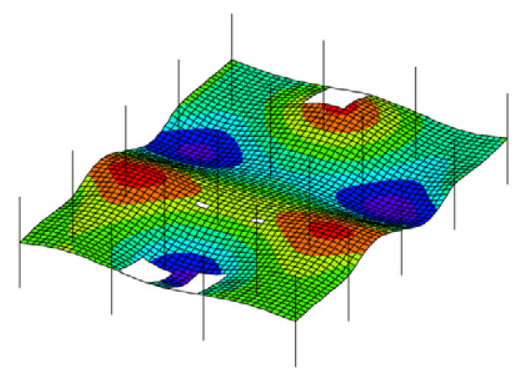

Mode (6)
Freq. $=9.18 \mathrm{~Hz}$

Fig. 5. The first six mode shapes of the concrete building floor [5] (these models show a combination of simple wave shape in each floor panel).

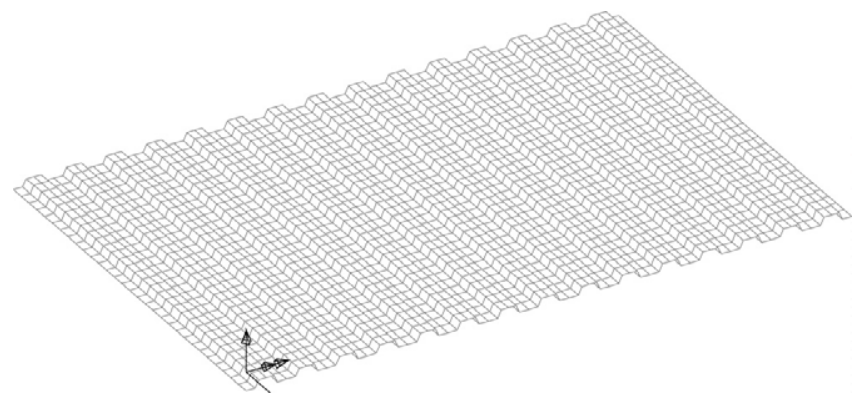

Fig. 6(a). Steel-sheet model (thin shell elements).

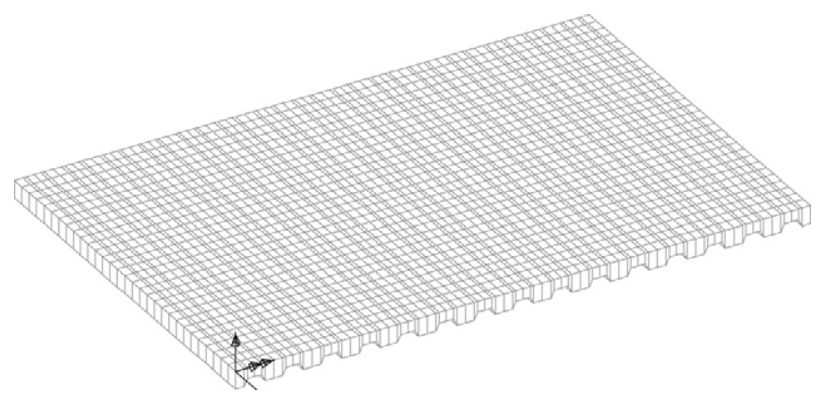

Fig. 6(b). Concrete slab model (3D-solid elements).

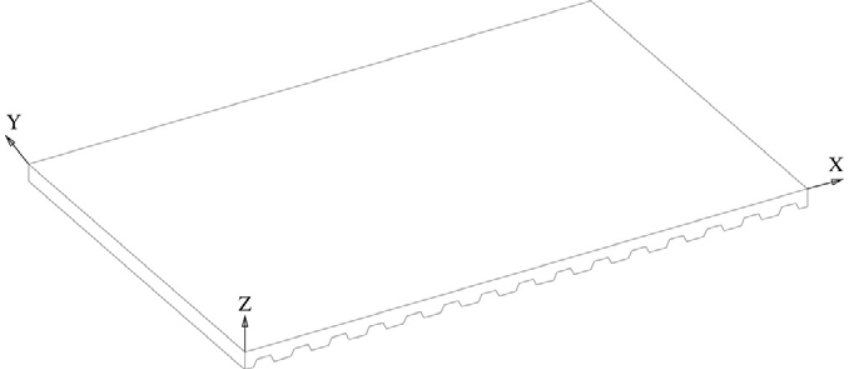

Fig. 6(c). 3D-model of a composite floor.

3D composite floor panel. The procedure to determine the orthotropic equivalent flat plate properties in the two directions is summarised as follows, where a unit length $1.0 \mathrm{~m}$ in each of the two perpendicular directions is considered.

\subsection{Section properties in the $x$-direction}

The cross-section in the $x$-direction consists of two sections, concrete slab and steel sheet, as shown in Fig. 7. The calculations of the area $(A)$ and the second moment $(I)$ of the sections are detailed as follows: 


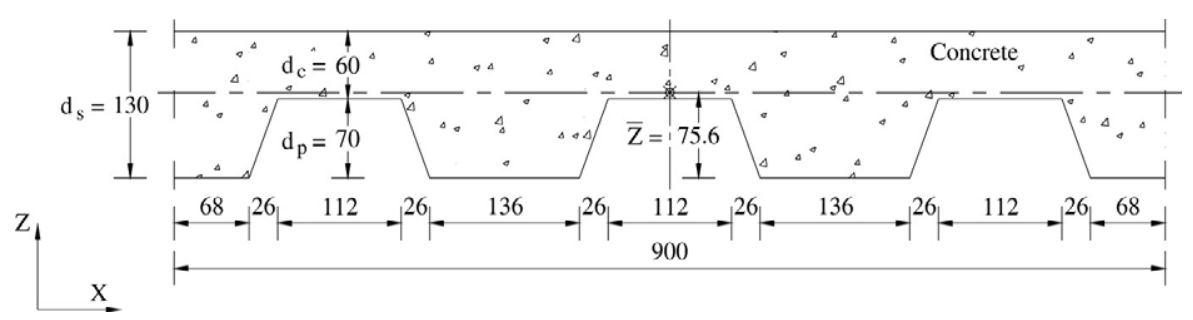

(a) The section of concrete.

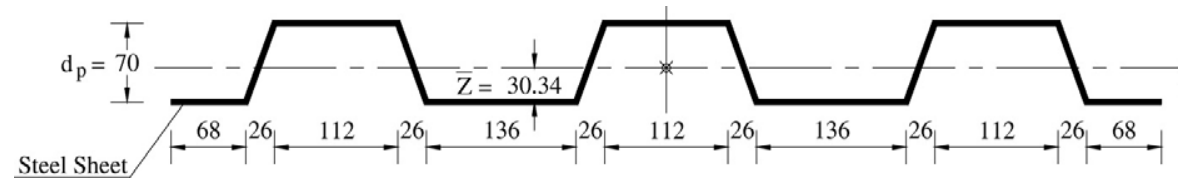

(b) The section of steel sheet.

Fig. 7. Components of the composite floor in the $x z$-plane (section A-A, dimension in mm).

- Calculate the position of the neutral axis of the concrete section, $\bar{Z}=7.56 \mathrm{~cm}$ measured from the bottom of the slab (Fig. 7(a)).

- Calculate the area $\left(A_{c}\right)$ and the second moment of area $\left(I_{c}\right)$ of the concrete cross-section and divide its values by the $0.90 \mathrm{~m}$ to convert it to $1.0 \mathrm{~m}$ unit length. The results are shown as follows

$$
A_{c}=978.0 \mathrm{~cm}^{2}, \quad I_{c}=1.257 \times 10^{4} \mathrm{~cm}^{4} \text {. }
$$

- Select the location of the neutral axis $(\bar{Z}=3.034 \mathrm{~cm})$, area $\left(A_{s}=11.78 \mathrm{~cm}^{2}\right)$ and the second moment of area $\left(I_{S}=54.80 \mathrm{~cm}^{4}\right)$ of the steel sheet (Fig. 7(b)) [15].

- Calculate the location of the neutral axis $(\bar{Z})$ of the composite section taking into account the modular ratio of the steel to concrete $(n=6.27)$ :

$$
\bar{Z}=\frac{978 \times 7.56+(11.78) \times 6.27 \times 3.034}{978+(11.78) \times 6.27}=7.245 \mathrm{~cm} \text {. }
$$

- Calculate the area $\left(A_{x}\right)$ and the second moment of area $\left(I_{x}\right)$ of the composite section (steel sheet and concrete) as an equivalent concrete section:

$$
\begin{aligned}
A_{x}= & 978.0+(11.78 \times 6.27)=1.051 \times 10^{3} \mathrm{~cm}^{2} \\
I_{x}= & {\left[1.257 \times 10^{4}+978 \times(7.56-7.245)^{2}\right.} \\
& +(54.8 \times 6.27)+(11.78 \times 6.27) \\
& \left.\times(3.034-7.245)^{2}\right]=1.432 \times 10^{4} \mathrm{~cm}^{4} .
\end{aligned}
$$

\subsection{Section properties in the $y$-direction}

The cross-sections of the deck parallel to the $y z$-plane have two different depths $\left(d_{c}=60\right.$ and $\left.130 \mathrm{~mm}\right)$ which needs to be converted equivalently to a single section. The properties of the two sections are:

- The location of the neutral axis, area and second moment of area for $d_{c}=60 \mathrm{~mm}$ section are:

$$
\begin{aligned}
& \bar{Z}_{1} \\
& =\frac{(6 \times 100) \times 3+[(100 \times 0.09) \times(0.045+6)] \times 6.27}{(6 \times 100)+(100 \times 0.09) \times 6.27} \\
& =3.262 \mathrm{~cm}
\end{aligned}
$$

$$
\begin{aligned}
A_{1}= & (6 \times 100)+(0.09 \times 100 \times 6.27)=6.564 \times 10^{2} \mathrm{~cm}^{2} \\
I_{1}= & \left\{\frac{100 \times 6^{3}}{12}+(6 \times 100) \times(3-3.262)^{2}\right. \\
& +\frac{100 \times 0.09^{3} \times 6.27}{12}+(100 \times 0.09 \times 6.27) \\
& \left.\times(6.045-3.262)^{2}\right\}=2.278 \times 10^{3} \mathrm{~cm}^{4} .
\end{aligned}
$$

- The location of the neutral axis, area and second moment of area for $d_{c}=130 \mathrm{~mm}$ section are:

$$
\begin{aligned}
\bar{Z}_{2}= & \frac{(13 \times 100) \times 6.5+[(100 \times 0.09) \times(0.045+13)] \times 6.27}{(13 \times 100)+(100 \times 0.09) \times 6.27} \\
= & 6.772 \mathrm{~cm} \\
A_{2}= & (13 \times 100)+(0.09 \times 100 \times 6.27) \\
= & 1.356 \times 10^{3} \mathrm{~cm}^{2} \\
I_{2}= & \left\{\frac{100 \times 13^{3}}{12}+(13 \times 100) \times(6.5-6.772)^{2}\right. \\
& +\frac{100 \times 0.09^{3} \times 6.27}{12}+(100 \times 0.09 \times 6.27) \\
& \left.\times(13.045-6.772)^{2}\right\}=2.063 \times 10^{4} \mathrm{~cm}^{4} .
\end{aligned}
$$

To calculate the bending stiffness of a unit in the $y$ direction, a simply supported beam model is considered which is subjected to uniform distributed load $(1.0 \mathrm{kN} / \mathrm{m})$ and has a span of $4.50 \mathrm{~m}$ and a width of $1.0 \mathrm{~m}$. According to the location of the deck support, there are two possible beam profiles and one fifth of the length of the beam profiles are shown in Fig. 8(a), (b). The beam element (BM3) is used to model the simply supported beam (Fig. 8(c), (d)).

The maximum defection of the simply supported beam ( $\left.\Delta_{\max }\right)$ subjected to the uniform distributed load is calculated using LUSAS. Then the equivalent thickness $\left(t_{\mathrm{eq}}\right)$ is determined using the following formulae.

$\Delta_{\max }=\frac{5 q L^{4}}{384 E_{c} I_{y}} \quad$ and $\quad I_{y}=\frac{1.0 \times t_{\mathrm{eq}}^{3}}{12}$.

Analysis shows that the two beam models give almost the same results. 


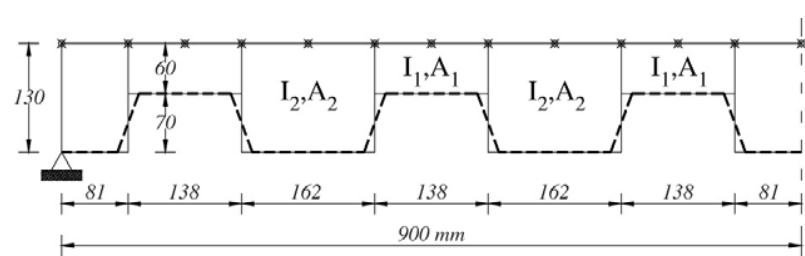

(a) Section-B1.

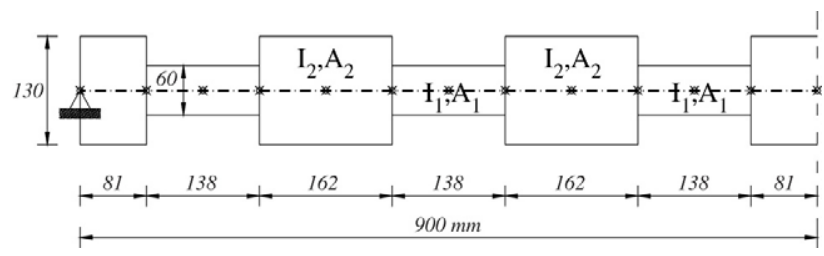

(c) FE-Model-B1.

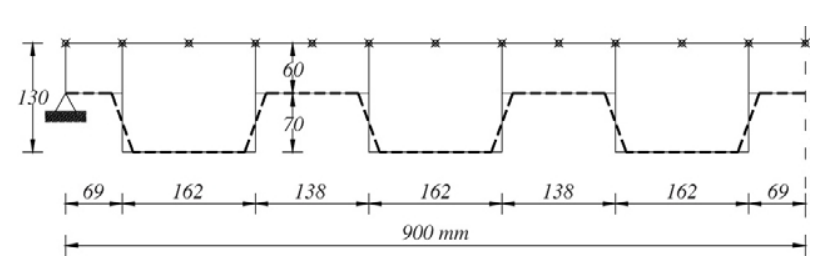

(b) Section-B2.

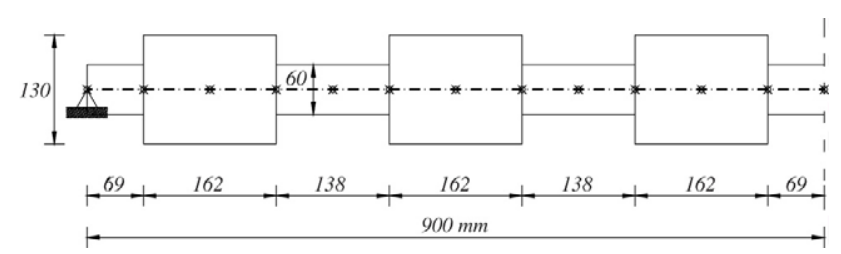

(d) FE-Model-B2.

Fig. 8. The two possible beam profiles and their FE models (dimension in $\mathrm{mm}$ ).

- Determine the ratio between the bending stiffness $\left(I_{x} \& I_{y}\right)$ in the two perpendicular directions of the composite floor. The ratio between the stiffnesses is as follow:

$$
\begin{aligned}
& I_{x}=1.432 \times 10^{4} \mathrm{~cm}^{4}, \quad I_{y}=4.379 \times 10^{3} \mathrm{~cm}^{4} \\
& R_{s}=I_{x} / I_{y}=3.271 .
\end{aligned}
$$

\subsection{Properties of an orthotropic equivalent flat panel}

In the calculation of displacement and frequency, the product of Young's modulus $(E)$ and the second moment of area $(I)$ are used. Thus, $\left(E I_{x}\right)$ and $\left(E I_{y}\right)$ can be equally expressed by $\left(E_{x} I\right)$ and $\left(E_{y} I\right)$. In this way, the composite plate is converted to an orthotropic flat plate, which can be easily modelled using a commercial FE software package. The related input data is given below:

- Young's modulus $=E_{c}$ (Young's modulus of the concrete)

$$
\begin{aligned}
E_{x}=R_{s} E_{c} & =33.5 \times 3.271 \mathrm{GPa} \text { and } \\
E_{y}=E_{c} & =33.5 \mathrm{GPa} .
\end{aligned}
$$

- Equivalent floor thickness $\left(t_{\mathrm{eq}}\right)=80.70 \mathrm{~mm}$

- Material density $\left(\rho_{e}\right)=[$ (Mass of the floor per unit area $\left.) / t_{\mathrm{eq}}\right]=2.539 \times 10^{3} \mathrm{~kg} / \mathrm{m}^{3}$.

Table 4 gives the comparison between the results of the orthotropic equivalent flat plate and the 3D-model of the composite deck panel. It can be seen from Table 4 that the equivalent orthotropic thin plate can provide reasonable results. Also, the FE analysis only takes less than $1 \%$ of CPU time as the 3D-model would need. In using this model hand calculation and simple FE analysis of a beam are only needed to define the properties of the equivalent orthotropic flat plate.

\section{Comparison between 3D composite panel model and equivalent plate models}

Results in Table 4 indicate that the composite deck floor can be modelled as an equivalent flat floor either isotropic or orthotropic. The comparison shows that:
- The frequencies and the displacements of the 3D model and the two simplified 2D models have a good agreement.

- The isotropic plate is slightly better than the orthotropic plate. However, the equivalent isotropic flat plate requires the modelling of a 3D composite deck panel.

- Significant saving in CPU time is achieved using the equivalent models.

In the development of the two flat plate models the following assumptions are used:

1. The mode shapes of a multi-panel floor are different and complicated but the shapes in each panel are simple, either concave or convex.

2. The two flat plate panel models can represent a 3D composite panel if they have the same maximum displacement.

3. The two equivalent flat plate models that are developed from a single panel can be applied to multi-panel floors.

The first assumption has been observed in several floor examples $[5,16]$. The second has been verified by the above comparison and the differences between the models are given in Table 4. The third assumption needs to be validated by comparing prediction and measurement of a real multi-panel composite floor. To validate the flat plate models a parametric study on examining the effects of several parameters is given in Section 6 and a comparison between measured and calculated floor natural frequencies of a profiled composite floor will be provided in Section 7.

\section{Parametric studies}

The two equivalent flat plate models are developed on the basis that the 3D model of the composite panel has four edges simply supported and is subjected to uniformly distributed loads. In addition, the shear modulus for the orthotropic plate uses the one for an isotropic plate. Therefore it is necessary to examine if the equivalence is affected by different boundary conditions, loading conditions and shear modulus and how much the thin steel sheet contributes to the global stiffness of the floor. 
Table 4

Comparison between the 3D-model and equivalent plate models

\begin{tabular}{|c|c|c|c|c|c|c|c|}
\hline Model & Freq $\left(f_{o}\right)(\mathrm{Hz})$ & Ratio & CPU time (s) & Max. disp. (mm) & Ratio & CPU time (s) & Thickness (mm) \\
\hline 3D-model (simply supported) & 33.03 & - & 329.6 & 1.734 & - & 114.0 & - \\
\hline Isotropic equivalent plate & 33.45 & 1.013 & 2.66 & 1.734 & 1.000 & 1.35 & 107.4 \\
\hline Orthotropic equivalent plate & 34.29 & 1.038 & 2.58 & 1.617 & 0.933 & 1.30 & 80.70 \\
\hline
\end{tabular}

Table 5

The effect of boundary conditions

\begin{tabular}{|c|c|c|c|c|c|}
\hline Model & $f_{o}(\mathrm{~Hz})$ & Ratio & $\Delta_{\max }(\mathrm{mm})$ & Ratio & $t_{\mathrm{eq}}(\mathrm{mm})$ \\
\hline 3D-model (4 sides fixed) & 66.58 & - & 0.423 & - & - \\
\hline Isotropic equivalent plate & 68.42 & 1.028 & 0.423 & 0.999 & 113.1 \\
\hline Orthotropic equivalent plate & 70.12 & 1.053 & 0.384 & 0.906 & 80.92 \\
\hline 3D-model (3 fixed sides and one side simply supported) & 65.35 & - & 0.434 & - & - \\
\hline Isotropic equivalent plate & 66.70 & 1.021 & 0.437 & 1.005 & 114.5 \\
\hline Orthotropic equivalent plate & 68.93 & 1.055 & 0.389 & 0.896 & 80.76 \\
\hline
\end{tabular}

Table 6

The effect of loading conditions

\begin{tabular}{|c|c|c|c|c|c|}
\hline Model & $f_{o}(\mathrm{~Hz})$ & Ratio & $\Delta_{\max }(\mathrm{mm})$ & Ratio & $t_{\mathrm{eq}}(\mathrm{mm})$ \\
\hline 3D-model (conc. load) & 33.03 & - & 0.442 & - & - \\
\hline Equivalent isotropic plate & 31.11 & 0.942 & 0.446 & 1.009 & 102.4 \\
\hline Equivalent orthotropic plate & 34.32 & 1.039 & 0.399 & 0.903 & 80.90 \\
\hline
\end{tabular}

\subsection{The effect of boundary condition}

Two other boundary conditions are considered, (a) a rectangular plate has four fixed edges and (b) a rectangular plate has three edges fixed and one side (short side) simply supported. The maximum deflections of the two cases due to the uniformly distributed load $\left(q_{o}\right)$ are given in Eqs. (4) and (5) respectively [14]:

$\Delta_{\max }=0.00220\left[\frac{q_{o} b^{4}}{D}\right]$

$\Delta_{\max }=0.00234\left[\frac{q_{o} b^{4}}{D}\right]$.

The comparison of the results between the 3D model and the equivalent plates for the three sets of boundary conditions are given in Tables 4 and 5. It can be noted that

- The equivalent thickness of a flat plate using the isotropic plate model varies about 5\%-6\% for the studied cases while the thickness of the orthotropic flat plate is almost constant.

- The isotropic plate model provides a very good solution. The errors of the orthotropic model are about $10 \%$ for the maximum displacement and 5\% for the fundamental natural frequency.

- The orthotropic model tends to be stiffer than the 3D-model.

\subsection{The effect of load condition}

A concentrated load is applied at the centre of the simply supported flat plate; its maximum displacement is Eq. (6) [14]:

$\Delta_{\max }=0.01531\left[\frac{P b^{2}}{D}\right]$.
$\Delta_{\max }$ is once again calculated using the 3D-model and Eq. (6) is used to determine the thickness of the equivalent isotropic plate. For the orthotropic equivalent plate, a simply supported beam model subjected to a central concentrated load $(1.0 \mathrm{kN})$ is considered to calculate the equivalent thickness. Table 6 summarises the calculated fundamental frequencies and the maximum displacements for the three models.

Comparing the results in Tables 4 and 6 leads to the following observations:

- As the equivalency is achieved based on the same maximum displacement, the displacement calculated using the isotropic model always gives very good agreement.

- The orthotropic model leads to a stiffer plate, but the equivalence based on the distributed loading leads to smaller errors, $1 \%$ for the displacement and $4 \%$ for the fundamental natural frequency, than the concentrated loading, $10 \%$ and $4 \%$ respectively.

\subsection{The effect of shear modulus}

The shear modulus $\left(G_{\text {iso }}\right)$ for isotropic plates is used for the orthotropic plate and is

$G_{\text {iso }}=\frac{E_{\mathrm{y}}}{2(1+v)}$.

Three other shear moduli in Eq. (7) are also considered. The effect of the shear modulus are examined linking to boundary and loading conditions which are discussed in the last two 
Table 7

The effect of different shear moduli on the orthotropic equivalent plate model

\begin{tabular}{|c|c|c|c|c|c|c|}
\hline Model & $\left(G^{*} / G_{\text {iso }}\right)$ & $f_{o}(\mathrm{~Hz})$ & Ratio & $\Delta_{\max }(\mathrm{mm})$ & Ratio & $t_{\mathrm{eq}}(\mathrm{mm})$ \\
\hline \multicolumn{7}{|c|}{ Simply supported orthotropic plate subjected to uniformly distributed load } \\
\hline 3D-model & 1.00 & 33.03 & - & 1.734 & - & \multirow{5}{*}{80.70} \\
\hline Case $(1)\left(G_{\text {iso }}\right)$ & 1.00 & 34.29 & 1.038 & 1.617 & 0.933 & \\
\hline Case (2) $\left(G^{* 2}\right)$ & 0.833 & 33.92 & 1.027 & 1.653 & 0.953 & \\
\hline Case (3) $\left(G^{* 3}\right)$ & 0.862 & 33.99 & 1.029 & 1.646 & 0.949 & \\
\hline Case (4) $\left(G^{* 4}\right)$ & 0.203 & 33.08 & 1.002 & 1.736 & 1.001 & \\
\hline \multicolumn{7}{|c|}{4 Sides fixed orthotropic plate subjected to uniformly distributed load } \\
\hline 3D-model & 1.00 & 66.58 & - & 0.423 & - & \multirow{5}{*}{80.92} \\
\hline Case (1) $\left(G_{\text {iso }}\right)$ & 1.00 & 70.12 & 1.053 & 0.384 & 0.906 & \\
\hline Case (2) $\left(G^{* 2}\right)$ & 0.833 & 69.83 & 1.049 & 0.387 & 0.913 & \\
\hline Case (3) $\left(G^{* 3}\right)$ & 0.862 & 69.88 & 1.050 & 0.386 & 0.912 & \\
\hline Case (4) $\left(G^{* 4}\right)$ & 0.203 & 69.22 & 1.040 & 0.393 & 0.928 & \\
\hline \multicolumn{7}{|c|}{3 Sides fixed and one side simply supported orthotropic plate subjected to uniformly distributed load } \\
\hline 3D-model & 1.00 & 65.35 & - & 0.434 & - & \multirow{5}{*}{80.76} \\
\hline Case $(1)\left(G_{\text {iso }}\right)$ & 1.00 & 68.93 & 1.055 & 0.389 & 0.896 & \\
\hline Case (2) $\left(G^{* 2}\right)$ & 0.833 & 68.65 & 1.051 & 0.392 & 0.902 & \\
\hline Case (3) $\left(G^{* 3}\right)$ & 0.862 & 68.70 & 1.051 & 0.391 & 0.901 & \\
\hline Case (4) $\left(G^{* 4}\right)$ & 0.203 & 68.08 & 1.042 & 0.397 & 0.915 & \\
\hline \multicolumn{7}{|c|}{ Simply supported orthotropic plate subjected to a concentrated load } \\
\hline 3D-model & 1.00 & 33.03 & - & 0.442 & - & \multirow{5}{*}{80.90} \\
\hline Case $(1)\left(G_{\text {iso }}\right)$ & 1.00 & 34.32 & 1.039 & 0.399 & 0.903 & \\
\hline Case (2) $\left(G^{* 2}\right)$ & 0.833 & 33.92 & 1.027 & 0.409 & 0.927 & \\
\hline Case (3) $\left(G^{* 3}\right)$ & 0.862 & 33.99 & 1.029 & 0.407 & 0.922 & \\
\hline Case (4) $\left(G^{* 4}\right)$ & 0.203 & 33.08 & 1.002 & 0.435 & 0.984 & \\
\hline
\end{tabular}

sections.

$$
G^{*}=\left[\begin{array}{c}
\frac{5}{6} G_{\text {iso }} \\
\frac{5}{(6-v)} G_{\text {iso }} \\
\frac{E_{y} \sqrt{e}}{2(1+v \sqrt{1 / e})}, e=E_{y} / E_{x}
\end{array}\right] \Rightarrow\left[\begin{array}{l}
G^{* 2}[17] \\
G^{* 3}[17] \\
G^{* 4}[18]
\end{array}\right] .
$$

Table 7 shows the comparison between the results of the orthotropic equivalent flat plate using different shear moduli. It can be seen from Table 7 that using $G^{* 4}$ provides the best results for all the cases studied.

\subsection{The effect of steel sheet}

It is useful to know how much the steel sheet contributes to the global stiffness of the composite floor. Therefore, the 3Dmodel of the composite panel, as discussed in Section 3.1, is used again but without taking the steel sheet. Table 8 compares the fundamental natural frequency and maximum displacement of the plate with and without the steel sheet. It can be seen from Table 8 that removing the steel sheet increases the maximum displacement about $16 \%$ and reduces the fundamental natural frequency about $5 \%$. This comparison indicates that the steel sheet cannot be neglected from the modelling. The steel sheet is thin and has small area compared to the concrete part. However, the elastic modulus of the steel sheet is 6-7 times that of concrete and the location of the sheet is relatively far from the neutral axis of the composite section.
Table 8

The effect of steel sheet

\begin{tabular}{lcc}
\hline Model of the composite panel & $f_{o}(\mathrm{~Hz})$ & $\Delta_{\max }(\mathrm{mm})$ \\
\hline 3D-model with steel sheet & 33.03 & 1.734 \\
3D-model without steel sheet & 31.39 & 2.009 \\
Ratio & 0.950 & 1.159 \\
\hline
\end{tabular}

\subsection{Summary}

The parametric studies conclude that

- A simply supported plate subject to uniformly distributed loads is reasonable to be used to obtain the basic data of the two equivalent flat plate models.

- The shear modulus for the equivalent isotropic plate is given in Eq. (7) as conventionally used and for the orthotropic plate it is suggested to use $G^{* 4}$.

- The steel sheet of a composite plate should be considered in modelling as its contribution to the global stiffness of the plate cannot be neglected.

\section{Modelling a profiled composite floor}

After the models of composite floors are developed, or the input data is determined, a typical composite floor in the Cardington test building can be modelled. A floor-column model is directly used following the experience of modelling a multi-panel concrete floor $[5,13]$. The floor-column model considers the concrete slab, the steel sheets, the beams and the columns in the upper and lower storeys and linked to the floor. The upper and lower columns have the same height of 


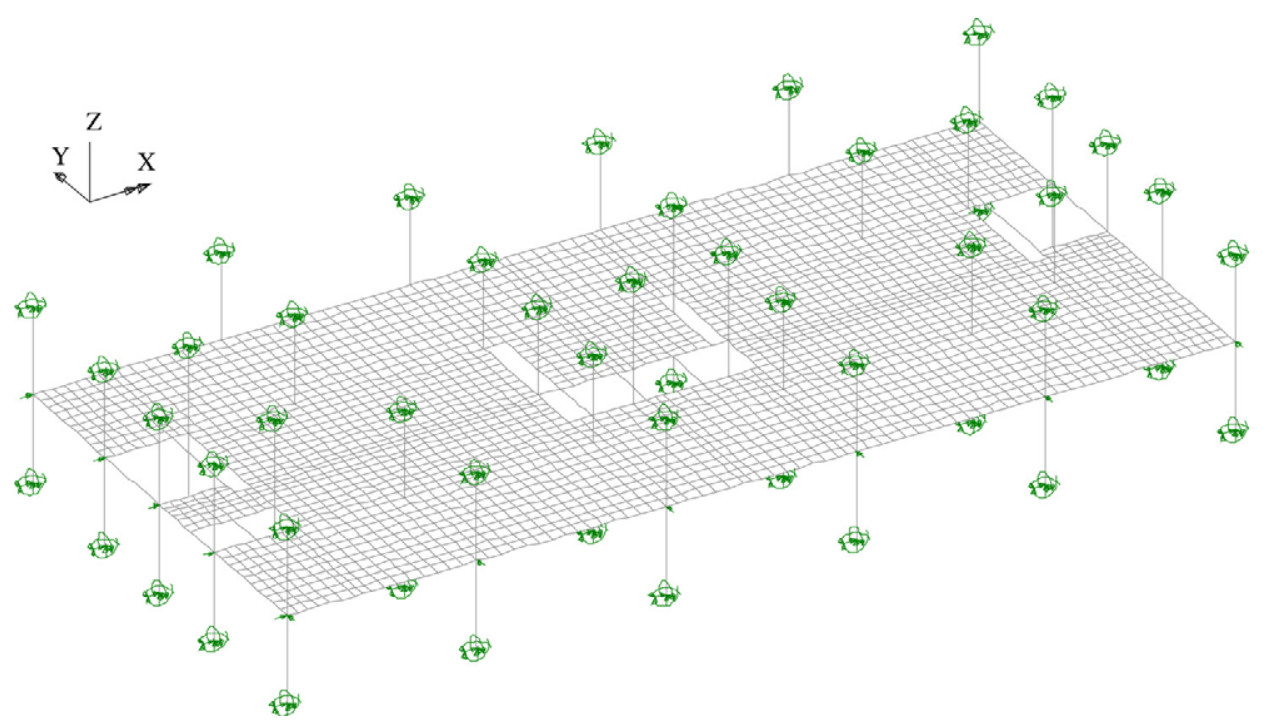

Fig. 9. Floor-column model of the composite floor.

$4.1875 \mathrm{~m}$. The other ends of all the columns are assumed to be fixed to the lower and upper floors as shown in Fig. 9.

\subsection{Effect of concrete slab thickness}

The Cardington test building used normal, unpropped composite construction and was constructed under normal site conditions. Like many other floors, the slab thickness was rather variable. Rose et al. [19] and Peel-Cross et al. [12] conducted a survey of the thickness of the building slab and concluded that the thickness of the floor slab varied quite considerably from the nominal $130 \mathrm{~mm}$ specified in the design and was on average well in excess of this value. It was found that the slab thickness was up to $30 \mathrm{~mm}$ greater than the design thickness and the overall average thickness was $146 \mathrm{~mm}[20,21,12]$. Therefore, the two thicknesses of the continuous upper portion of the concrete slab are used for the finite element modelling of the full-scale composite floor. The first one is the nominal design depth $d_{c}=60 \mathrm{~mm}$ (Model 1) and the second is the actual measured overall average depth $d_{c}=76 \mathrm{~mm}$ (Model 2).

The following material properties are used based on the test results for the steelwork and the concrete:

- The elastic modulus of steel is $210 \mathrm{GPa}$.

- The elastic modulus of concrete test samples is $33.5 \mathrm{GPa}$.

- The floor mass in a unit area is detailed as follows [20]:

- Concrete floor: $=208 \mathrm{~kg}$.

- Steel $=20 \mathrm{~kg}$.

- Additional weight $=55 \mathrm{~kg}$.

- Total mass in a unit area $=288 \mathrm{~kg} / \mathrm{m}^{2}$.

- The equivalent mass density = (total mass in a unit area $\left./ t_{\mathrm{eq}}\right) \mathrm{kg} / \mathrm{m}^{3}$.

The equivalent isotropic flat plate model is used to obtain the equivalent thickness of the floor (107.44 mm for Model 1 and $121.45 \mathrm{~mm}$ for Model 2).

The first six natural frequencies calculated for the two models are shown in Table 9. The mode shapes of the floor
Table 9

The calculated first six natural frequencies of Model 1 and Model 2

\begin{tabular}{llll}
\hline $\begin{array}{l}\text { Mode } \\
\text { no. }\end{array}$ & $\begin{array}{l}\text { Model 1 (M1) (design } \\
\text { thickness) }\end{array}$ & $\begin{array}{l}\text { Model 2 (M2) (actual } \\
\text { thickness) }\end{array}$ & Ratio (M1/M2) \\
\hline 1 & 6.89 & 7.35 & 0.938 \\
2 & 7.16 & 7.67 & 0.933 \\
3 & 7.24 & 7.76 & 0.933 \\
4 & 7.56 & 8.17 & 0.925 \\
5 & 7.57 & 8.25 & 0.917 \\
6 & 8.01 & 8.70 & 0.920 \\
\hline
\end{tabular}

model, which has the averaged measured slab thickness, are shown in Fig. 10.

It can be seen from Table 9 and Fig. 10 that:

- The natural frequencies of Model 2 (using the actual averaged thickness) are about $7.0 \%$ higher than these of Model 1 (using the designed thickness).

- There are significant variations between the shapes of the six modes. However, the mode shape in each panel is still simple, either concave or convex. Therefore, it is reasonable that only a single panel is investigated to obtain the equivalent flat plate models.

\subsection{Comparison between FE and experimental results}

Dynamic tests on the composite floor were conducted [22]. The natural frequency of the composite floor was measured on the shaded area as shown in Fig. 4. An impact vibration was conducted at the centre of the test area by which the natural frequency was measured at $8.50 \mathrm{~Hz}$. The impact was induced by an individual jumping once at the centre of the panel.

The vibration induced on the test area would generate the vibration mode in which the maximum movement would occur in the test area rather than anywhere else. Therefore, each of the calculated vibration modes is examined and the fourth mode is identified to match the generated vibration, which is shown in Fig. 10. The comparison between the calculated and measured natural frequency of the composite floor is given in Table 10. 

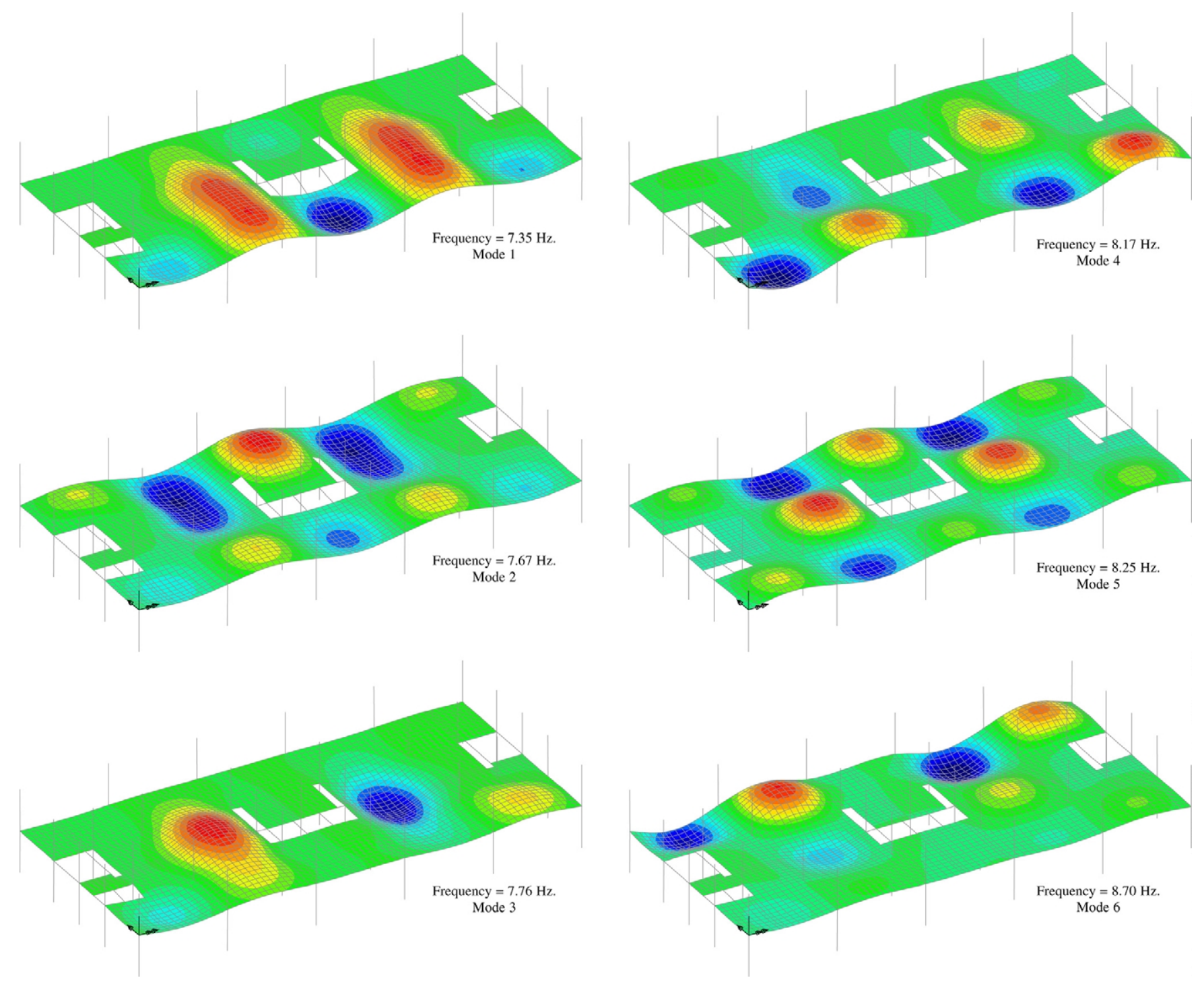

Fig. 10. The mode shapes (1-6) of the composite floor (Model 2).

Table 10

Comparison between calculated and measured frequency

\begin{tabular}{llll}
\hline Mode shape & Model 1 & Model 2 & Experiment \\
\hline Mode 4 & 7.56 & 8.17 & 8.50 \\
Ratio & 0.889 & 0.962 & - \\
\hline
\end{tabular}

The difference between the predications and the measurement may be caused due to the following reasons:

- The increased thickness of the concrete was due to and proportional to the deformation of the steel sheets during the construction. In the analysis, the average thickness (146 mm) was used rather than the actual thickness, the largest at the centre and smallest at the supports, which would underestimate the stiffness of the floor, thus the natural frequency of the floor.

- The partitions and staircase nearby the test panel of the floor were not considered in the calculation, which may slightly increase the stiffness of the floor.

\subsection{Effect of eccentricity}

The locations of neutral axes of the composite floor system will affect the calculated stiffness of the system. However, the locations are unlikely to be determined accurately as it is not clear what is the width of the composite floor should be considered in the dynamic analysis. Therefore, a parametric study on the locations of the neutral axes of the beams and floors is conducted to examine their effects on the dynamic behaviour of the composite floor. Four different locations of the neutral axis for Model 2 are studied as follows:

Location 1: The neutral axis is located at the mid-plane of a plate panel for all floor panels. Therefore there are no eccentricities for all floor panels and the eccentricities for all beams are the sum of a half of the beam height and a half of the plate thickness.

Location 2: The neutral axes are placed at the bottom surface of all floor panels. Therefore the eccentricities are a half of the plate thickness for all floor panels and a half of the height of the beam for all beams. 
Table 11

Natural frequencies of Model 2 with four different eccentricities

\begin{tabular}{lllll}
\hline Mode no. & Case 1 & Case 2 & Case 3 & Case 4 \\
\hline 1 & 7.35 & 7.34 & 7.34 & 5.44 \\
2 & 7.67 & 7.67 & 7.66 & 5.72 \\
3 & 7.76 & 7.75 & 7.75 & 5.82 \\
4 & 8.17 & 8.17 & 8.18 & 6.26 \\
5 & 8.25 & 8.25 & 8.24 & 6.44 \\
6 & 8.70 & 8.69 & 8.68 & 6.78 \\
\hline
\end{tabular}

Table 12

Properties of the orthotropic equivalent composite floor

\begin{tabular}{|c|c|c|c|c|}
\hline \multirow[t]{2}{*}{ Model } & $\begin{array}{l}\text { Thickness } \\
\left(t_{\mathrm{eq}}\right)(\mathrm{mm})\end{array}$ & $\begin{array}{l}\text { Stiffness ratio } \\
\left(R_{S}\right)\end{array}$ & $\begin{array}{l}\text { Mass density } \\
\left(\mathrm{kg} / \mathrm{m}^{3}\right)\end{array}$ & $\begin{array}{l}\text { Young's modulus } \\
\left(\mathrm{N} / \mathrm{m}^{2}\right)\end{array}$ \\
\hline & & & & $\left(E_{x}\right)$ \\
\hline
\end{tabular}

Location 3: The neutral axis is located at a distance of a half of the plate thickness below the bottom surface of all floor panels. Thus the eccentricities are the plate thickness for all floor panels and the difference between a half of the height of the beam and the plate thickness for all beams.

Location 4: No eccentricities for all floor panels and beams are considered.

The first location of the neutral axis is adopted in Sections 7.1, 7.2 and 7.4.

Table 11 shows the calculated first six natural frequencies of Model 2 with four different eccentricities for slab and beams. The comparison indicates that:

- The floor model without considering eccentricities significantly underestimates the natural frequencies of the floor system. The ratios of natural frequencies of the floor without to with considering eccentricity vary from $74 \%$ to $78 \%$ for the first six modes of the floor.

- The values of the natural frequencies of the studied floor are not sensitive to the location of the neutral axes of the slab and beam sections as long as the eccentricity is taken into account.

- The mode shapes of the floor model with and without considering eccentricity are almost the same but the order of some modes is altered.

\subsection{Comparison between isotropic and orthotropic models}

The properties of the equivalent orthotropic floor model are calculated and given in Table 12. The full floor is analysed using the above data and the mode shapes and frequencies are calculated. A comparison between the first six calculated natural frequencies of the isotropic and the orthotropic floor models, considering the beam eccentricity, is given in Table 13.

It can be seen from Table 13 that the frequencies of the isotropic and orthotropic floor models are close and their frequency ratio ranges between $94 \%$ to $97 \%$ for the first six modes using the second floor model $\left(d_{c}=76 \mathrm{~mm}\right)$. It is clear that both models are reasonable for investigating the dynamic behaviour of the full-scale composite floor and the isotropic floor model is better than the orthotropic floor model.
Table 13

Comparison between frequencies of isotropic and orthotropic floor models

\begin{tabular}{llll}
\hline Mode no. & $\begin{array}{l}\text { Isotropic floor } \\
\text { model freq }(\mathrm{Hz})\end{array}$ & $\begin{array}{l}\text { Orthotropic floor } \\
\text { model freq }(\mathrm{Hz})\end{array}$ & $\begin{array}{l}\text { Ratio } \\
\text { (Orthotropic/isotropic) }\end{array}$ \\
\hline 1 & 7.35 & 6.94 & 0.944 \\
2 & 7.67 & 7.27 & 0.948 \\
3 & 7.76 & 7.29 & 0.940 \\
4 & 8.17 & 7.86 & 0.962 \\
5 & 8.25 & 7.94 & 0.962 \\
6 & 8.70 & 8.43 & 0.969 \\
\hline
\end{tabular}

\section{Conclusions}

An equivalent isotropic and an orthotropic flat plate models are developed based on a sophisticated 3D-model of a composite floor panel. A parametric study is conducted to examine the quality of the flat plate models. These models are also used to predict the dynamic behaviour of a fullscale profiled composite floor and compare the calculated and measured frequencies of the floor.

The study shows the two simplified equivalent flat plate models can be used to study the dynamic behaviour of profiled composite floors.

It is also concluded from the study that:

- Significant saving in CPU time can be achieved using the equivalent flat plate models.

- The isotropic flat floor model is more accurate than the orthotropic flat floor model, but it requires the calibration using a 3D composite panel model.

- The steel sheet in a composite floor should be considered in modelling as its contribution to the global stiffness of the composite floor is not small, about $16 \%$ of the total stiffness in the 3D panel model.

- Consideration of the eccentricity of the beams and slabs in the analysis is important as it can significantly affect the predicted frequencies and change the order of vibration modes. A parametric study shows that the locations of the neutral axes of beams and slabs are not sensitive to the natural frequency as long as they are reasonably considered.

- The thickness of a floor also significantly affects the prediction of the natural frequencies of the floor. It should be aware that the actual floor thickness after construction can be different from the designed one.

\section{Acknowledgment}

The work reported in this paper has been conducted as part of the project, Prediction of floor vibration induced by walking loads and verification using available measurements, funded by the UK Engineering and Physical Sciences Research Council (EPSRC grant No GR/S 74089), whose support is gratefully acknowledged.

\section{References}

[1] Easterling WS, Porter ML. Steel-deck-reinforced concrete diaphragms I. Journal of Structural Engineering, ASCE 1994;120(2):560-75. 
[2] Mullett DL. Composite Floor Systems. Oxford: Blackwell Science Ltd.; 1998.

[3] BSI. Structural use of steelwork in building, Part 4: Code of practice for design of composite slabs with profiled steel sheeting. BS 5950. London: British Standards Institution; 1994.

[4] da Silva JGS, da CP Soeiro FJ, da S Vellasco PCG, de Andrade SAL, Werneck R. Dynamical analysis of composite steel decks floors subjected to rhythmic load actions. In: Proceedings of the eighth international conference on civil and structural engineering computing. United Kingdom: Civil-Comp Press Stirling; 2001 p. 34.

[5] El-Dardiry E, Wahyuni E, Ji T, Ellis BR. Improving FE models of a longspan flat concrete floor using natural frequency measurements. Computers \& Structures 2002;80(27-30):2145-56.

[6] Armer GST, Moore DB. Full-scale testing on complete multi-storey structures. The Structural Engineer 1994;72(2):30-1.

[7] Ellis BR, Ji T. Dynamic testing and numerical modelling of the Cardington steel framed building from construction to completion. The Structural Engineer 1996;74(11):186-92.

[8] Bravery PNR. Cardington large building test facility - construction details for the first building. 1994.

[9] FEA Ltd. LUSAS User Manual; Kingston-upon-Thames. 1993.

[10] Zhaohui H, Burgess IW, Plank RJ. Three dimensional analysis of composite steel-framed building in fire. Journal of Structural Engineering, ASCE 2000;126(3):389-97.

[11] Zhaohui H, Burgess IW, Plank RJ. Effective stiffness of modelling composite concrete slabs in fire. Engineering Structures 2000;22(9): 1133-44.
[12] Peel-Cross J, Rankin GIB, Gilbert SG, Long AE. Compressive membrane action in composite floor slabs in the Cardington LBTF. Proceedings of the Institution of Civil Engineers, Structures \& Buildings 2001;146(2): $217-26$

[13] El-Dardiry E. Floor vibration induced by walking loads. Ph.D. thesis, UMIST; 2003.

[14] Timoshenko SP, Woinowsky-Krieger S. Theory of plates and shells. second ed. McGraw-Hill; 1959.

[15] PMF. Precision metal forming, composite floor decking systems, Technical literature. Cheltenham (Gloucestershire): PMF Ltd.; 1994.

[16] Ji T, El-Dardiry E. Vibration assessment of a floor at SynagogueCazenove road, London. Client report, UK: The Manchester Centre for Civil \& Construction Engineering, UMIST; 2002.

[17] Whittrick WH. Analytical, Three-dimensional elasticity solutions to some plate problems, and some observations on Mindlin's plate theory. International Journal of Structures 1987;23(4):441-64.

[18] Szilard R. Theory and analysis of plates. Englewood Cliffs, NJ: PrenticeHall; 1974.

[19] Rose PS, Burgess IW, Plank RJ. A slab thickness survey of the Cardington test frame. Res. rep. DCSE/96/F/7, UK: Dept. of Civil and Structural Engineering, University of Sheffield; 1996.

[20] Gibb P, Currie DM. Construction loads for composite floor slabs, In: The first Cardington conference. 1994.

[21] Ji T, Ellis BR. Dynamic characteristics of the Cardington building from construction to completion. Client report. Watford (UK): Building Research Establishment; 1995.

[22] Ellis BR, Ji T. Loads generated by jumping crowds: experimental assessment. BRE Information Paper IP 4/02. 2002. 12 pages. 